\title{
Recent Echocardiography Parameters for Predicting Better Functional Result After Mitral Valve Correction Surgery in Patients with Primary Mitral Regurgitation
}

\author{
Indah Puspita? ${ }^{1}$ Amiliana M Soesanto², Estu Rudiktyo², Rina Ariani², BRM Ario S Kuncoro²
}

\footnotetext{
' Department of Cardiology and Vascular Medicine, Mohammad Hoesin General Hospital,Palembang ${ }^{2}$ Department of Cardiology and Vascular Medicine, Faculty of Medicine, Universitas Indonesia/ National Cardiovascular Center Harapan Kita, Jakarta

Correspondence: Indah Puspita,

Department of Cardiology and

Vascular Medicine, Mohammad

Hoesin General Hospital,

Palembang.

Email:viva_indah@yahoo.com
}

\begin{abstract}
Objectives: We analyzed whether some echocardiographic parameters are good predictors of functional result after mitral valve correction surgery.

Background: Ejection fraction was not the only parameter to decide optimal time for surgery, nor an indicator for a better functional result after surgery. Severity measurement being a main consideration in surgery decision. Reduced left ventricle dimension after surgery reflect a better functional result.

Methods: In 2019, 67 patients was included in this analysis. Age 53 (I7-67) years, male $52,2 \%$. All patients are with severe primary mitral regurgitation and treated by mitral valve surgery (mitral valve repair or replacement). Retrospective echocardiographic analysis was performed, to find the best parameter for predicting better functional outcome after surgery.

Results: Data was collected from January to December 2019. From 262 primary mitral valve surgery underwent in National Heart Center Harapan Kita, there was 67 patients included, the other was excluded due to probability of secondary mitral regurgitation mechanism, concomitant congenital heart disease and or other significant valves disease, missing post-surgery data due to referral flow to the prior hospital and less complete echocardiographic views for further analysis. In bivariate analysis, end-diastolic volume (EDV) and regurgitant volume (RV) were strong predictor of decreasing left ventricle diameter after surgery ( $0.000 \mathrm{I}$ and $\mathrm{p} 0.05$ ). End-diastolic volume $133.5 \mathrm{ml}$ or more is predictive for decreasing left ventricle diameter if surgery was conducted (sensitivity $87.3 \%$, sensitivity $66.7 \%$ ).

Conclusion: EDV and RV found to be good predictors for functional outcome of primary mitral valve surgery than other echocardiographic parameters. Measuring EDV before deciding timing of surgery will be helpful in targeting better functional result after surgery.
\end{abstract}

(Indonesian J Cardiol. 202।;42: I-7)

Keywords: mitral regurgitation, end-diastolic volume, regurgitant volume 


\section{Introduction}

$\mathrm{E}$

arly compensation of mitral regurgitaion (MR) showed in acute MR due to Frank-Starling mechanism utilisation, that gradually followed by chronic remodelling process; increase of left ventricle dimension. The adapted compensatory process is possible to be failed, causing left ventricle disfunction and transition to became chronic decompensation phase of MR. ${ }^{1,2}$. Advanced phase of chronic MR signed by existing of some heart failure symptoms, but sometime the progression of those symptoms was not reported due to less self awareness of the patient. It become priority to detect functional and structural remodelling of left ventricle as early as possible, before permanent left ventricle disfunction occur. Moreover, decision for appropriate time for surgery will prevent advanced decompensation phase. Decompensation phase of MR mainly characterized by progressive and substantial left ventricle dilatation, increase of left ventricle pressure, increase of systolic wall stress and ejection fraction reduction $<50 \%$. Management of MR was depend on severity of MR based on echocardiographic measurement. Some parameters for MR severity measurement are regurgitant volume, MR fraction, effective regurgitant orifice area (EROA). ${ }^{3}$ Some research analyze parameters to predict the outcome of surgery, such as left atrial dilatation, ${ }^{4}$ atrial fibrillation, ${ }^{5}$ pulmonary hypertension, ${ }^{6}$ ejection fraction, ${ }^{7,8,9}$ end systolic volume ${ }^{10}$ and myocardial strain. ${ }^{11,12}$ More research with different sample characteristics in finding significant parameters and value were needed to support decision of optimal timing for surgery, to finally achieve better functional result after surgery.

\section{Methods}

\section{Study Design}

This study design is cross-sectional study. The data from surgery medical records of 262 patients with severe primary MR who underwent repair or replacement surgery were retrospectively listed. All the patients were examined and underwent the surgery at National Heart Center Harapan Kita, Jakarta, Indonesia between January and December 2019. Amount of 195 patients were excluded due to combined other significant valve disease, congenital heart disease and possibility of secondary mechanism of MR. Patients with loss followup and uncomplete echocardiographic data were also excluded.

\section{Echocardiography}

Echocardiography was performed, trans-thoracal and trans-esophageal. All subjects was examined with conventional 2-dimensional, M-Mode, conventional and color doppler ultrasonography by cardiologist and experienced sonographer, based on American Society Echocardiography guidelines ${ }^{13}$. Severe MR was obtained from echocardiographic image, include

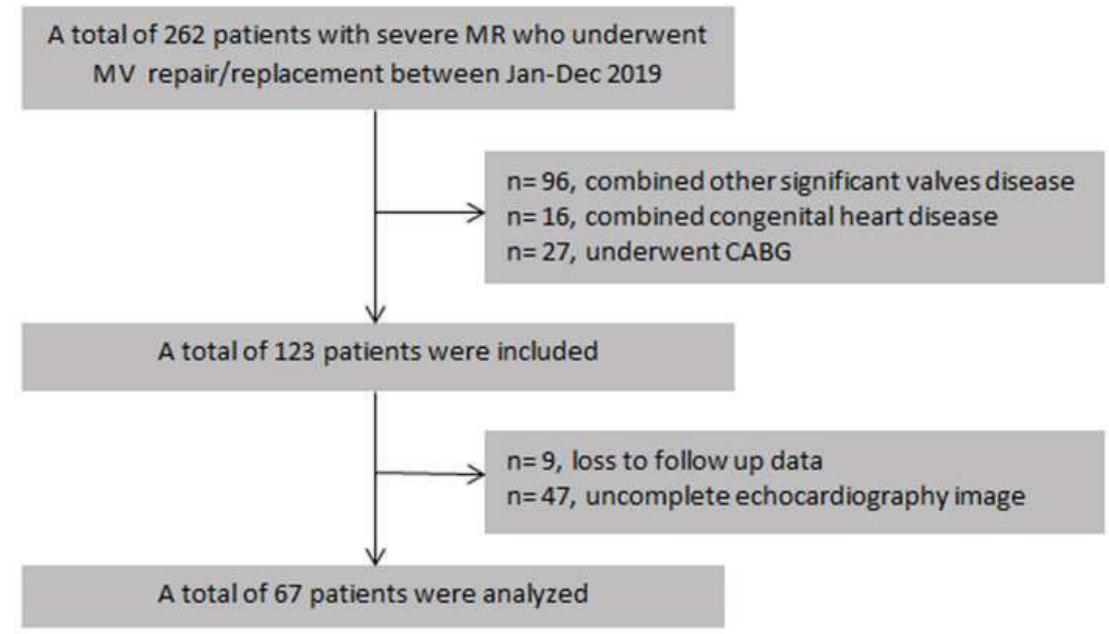

Figure 1. Study Population 
Table 1. Baseline characteristics and echocardiographic parameter

\begin{tabular}{lc}
\hline & $\mathbf{N}=\mathbf{6 7}$ \\
& Mean/Median + SD \\
\hline Age, years & $33(17-67)$ \\
Male $\mathrm{n}(\%)$ & $35(52.2)$ \\
Female $\mathrm{n}(\%)$ & $32(47.8)$ \\
Body surface area, m2 & $1.6 \pm 2$ \\
LVEF, \% & $67.5 \pm 7.0$ \\
MVD, mm & $4.3(3.4-7.8)$ \\
LVEDd,mm & $58.4 \pm 7.7$ \\
MSV, ml & $542.8 \pm 266.2$ \\
RV, ml & $77(10-504)$ \\
EDV, ml & $173.1 \pm 52.9$ \\
MR VTI, m/s & $120.8 \pm 31.7$ \\
MV VTI, m/s & $40.6(16-92.1)$ \\
MR mean PG, mmHg & $46.2 \pm 20.6$ \\
MR maximal velocity, m/s & $4.2(4-6.1)$ \\
MV mean PG, mmHg & $4(5-32)$ \\
MV maximal velocity, m/s & $1.2(2-10.8)$ \\
LA diameter, mm & $48.6(28-87)$ \\
LAVI, ml/m2 & $89(35-889.5)$ \\
\hline
\end{tabular}

$L V E F$, Left ventricle ejection fraction. MVD, Mitral valve diameter. MSV, Mitral stroke volume. RV, Regurgitant volume. $E D V$, End diastolic volume. MR VTI, Mitral regurgitation velocity time integral. MV VTI, Mitral valve velocity time integral. PG, Pressure gradient. LA, Left atrium. LAVI, Left atrium volume index

structural (severe valve lesions, dilated left ventricle and left atrium size), qualitative doppler (large central jet or eccentric wall impinging jet, large flow convergence throughout systole), semiquantitative (vena contracta width $>7 \mathrm{~cm}$, sometime accompanied by systolic flow reversal, E-wave dominant $>1.2 \mathrm{~m} / \mathrm{s}$ of mitral inflow) and quantitative (EROA $>0.40 \mathrm{~cm}^{2}$, regurgitant volume $>60 \mathrm{~mL}$, regurgitant fraction $>50 \%) .{ }^{14} \mathrm{LV}$ end-diastolic dimension and LV end-diastolic volume (EDV) was calculated by using M-mode, 2 dimensional image. LV end-diastolic dimension was calculated pre and post surgery. Decreasing LV dimension indicate an improvement functionally, the same or increase dimension not indicate a better functional result after surgery.

\section{Statistical Analysis}

Statistical analysis was performed using SPSS software (SPSS, Chicago, IL). Data are expressed as mean + SD for normal data, and median (range) for abnormal data, with Kolmogorov-Smirnov test. Bivariate analysis
Table 2. Baseline characteristics according to decreasing left ventricle diameter after surgery

\begin{tabular}{|c|c|c|c|}
\hline \multirow{3}{*}{ Variables } & \multirow{2}{*}{\multicolumn{2}{|c|}{$\begin{array}{c}\text { Decreasing Left Ventricle } \\
\text { Diameter after surgery } \\
\text { (mean/median } \pm \text { SD) }\end{array}$}} & \multirow{3}{*}{ p-value } \\
\hline & & & \\
\hline & Yes & No & \\
\hline Age, years & $52(17-67)$ & $54.5(19-64)$ & 0.987 \\
\hline \multicolumn{4}{|l|}{ Sex } \\
\hline Male & $30(85.7)$ & $5(14.3)$ & \multirow[t]{2}{*}{0.624} \\
\hline Female & $25(78.1)$ & 7 (21.9) & \\
\hline Body surface area, $\mathrm{m} 2$ & $1.6 \pm .2$ & $1.5 \pm 2$ & 0.490 \\
\hline \multicolumn{4}{|l|}{ Type of MR Surgery } \\
\hline Repair & $42(91.3)$ & $4(8.7)$ & \multirow[t]{2}{*}{0.006} \\
\hline Replacement & $13(61.9)$ & $8(38.1)$ & \\
\hline
\end{tabular}

was used. Different probability treshold was obtain using receiver operating characteristic (ROC) curves as predictive model

\section{Results}

\section{Study population.}

Table 1 explain baseline characteristic of the patient. Median age is 53 years with range $18-67$ years, $52.2 \%$ are male. Mean pre-operative ejection fraction is 67.5 (+7)\%, EDV 173.1-952.9)ml, LA diameter 48.6 (2887) $\mathrm{mm}$, LAVI $89(35-889.5) \mathrm{ml} / \mathrm{m} 2$.

\section{Echocardiography.}

Significant decrease of left ventricle dimension after surgery was found in different type of surgery, whether repair or replacement surgery $(\mathrm{p}=0.006)$. There was also significant different of regugitant volume and end-diastolic volume for patients with and without decreasing of left ventricular dimension after surgery $(p=0.028$ and $p=0.001)$. Significant correlation was found between regurgitant volume and decreasing left ventricular dimension after surgery $(p=0.05)$. Stronger significant correlation was found between end-diastolic volume and decreasing left ventricular dimension after surgery $(p<0.001)$. Those correlations was explain in Table 4.

ROC curve was expressed in Figure 2. There is EDV tresh hold of $133.5 \mathrm{ml}$ (Sensitivity $87.3 \%$, specificity $66.7 \%$ ) for best functional outcome after surgery. 
Indonesian Journal of Cardiology

Table 3. Baseline echocardiographic parameters in patients with and without decreasing LV diameter after mitral valve surgery

\begin{tabular}{|c|c|c|c|}
\hline & \multicolumn{2}{|c|}{ Decreasing Left Ventricle Diameter after surgery } & \multirow{3}{*}{ p-value } \\
\hline & \multicolumn{2}{|c|}{$($ mean $/$ median $\pm S D)$} & \\
\hline & $\begin{array}{c}\text { Yes } \\
(\mathbf{n}=55)\end{array}$ & $\begin{array}{c}\text { No } \\
(n=12)\end{array}$ & \\
\hline LVEF, \% & $67.6 \pm 6.9$ & $67.1 \pm 7.7$ & 0.831 \\
\hline MVD, mm & $4.3(3.4-7.8)$ & $4.3(3.4-5.8)$ & 0.560 \\
\hline MSV, ml & $559.2 \pm 274.8$ & $467.6 \pm 216.9$ & 0.283 \\
\hline $\mathrm{RV}, \mathrm{ml}$ & $73(10-504)$ & $168.5(55-374)$ & 0.028 \\
\hline $\mathrm{EDV}, \mathrm{ml}$ & $182.8 \pm 51.4$ & $128.5 \pm 34.3$ & 0.001 \\
\hline MR VTI, $\mathrm{m} / \mathrm{s}$ & $119.6 \pm 31.2$ & $126.6 \pm 34.6$ & 0.492 \\
\hline MV VTI, m/s & $40.7(16-92.1)$ & $38.8(19.1-47.7)$ & 0.524 \\
\hline MR mean PG, mmHg & $44.7 \pm 20.6$ & $52.9 \pm 20.0$ & 0.216 \\
\hline MR maximal velocity, $\mathrm{m} / \mathrm{s}$ & $4.1(0.9-6.1)$ & $4.5(4-5.5)$ & 0.551 \\
\hline MV mean PG, mmHg & $4(0.8-32)$ & $3.7(5-7)$ & 0.550 \\
\hline MV maximal velocity, $\mathrm{m} / \mathrm{s}$ & $1.1(0.2-10.8)$ & $1.6(0.3-2.0)$ & 0.409 \\
\hline LA diameter, $\mathrm{mm}$ & $50(28-87)$ & $47.4(43-75)$ & 0.935 \\
\hline LAVI, $\mathrm{ml} / \mathrm{m} 2$ & $89(35-707)$ & $87.5(45-889.5)$ & 0.967 \\
\hline
\end{tabular}

Table 4. Correlation some baseline characteristics and echocardiographic parameters with decreasing LV dimension.

\begin{tabular}{lcc}
\hline & \multicolumn{2}{c}{$\begin{array}{c}\text { Decreasing LV diameter, } \\
\text { p Value, }\end{array}$} \\
& r & P \\
\hline & 0.02 & P value \\
\hline Age, years & -0.1 & 0.896 \\
Body surface area, m2 & 0.07 & 0.469 \\
Days after surgery to & & 0.591 \\
echocardiography & & \\
LVEF, \% & -0.06 & 0.645 \\
MVD, mm & 0.12 & 0.399 \\
MSV, ml & 0.12 & 0.392 \\
RV, ml & 0.27 & 0.05 \\
EDV, ml & 0.60 & 0.0001 \\
MR VTI, m/s & 0.15 & 0.264 \\
MV VTI, m/s & 0.20 & 0.134 \\
MR mean PG, mmHg & 0.22 & 0.106 \\
MR maximal velocity, m/s & 0.22 & 0.102 \\
MV mean PG, mmHg & 0.22 & 0.10 \\
MV maximal velocity, m/s & 0.24 & 0.07 \\
LA diameter, mm & 0.10 & 0.475 \\
LAVI, ml/m2 & 0.13 & 0.343 \\
\hline
\end{tabular}

\section{Discussion}

In this study, we found that regurgitant volume and end-diastolic volume were a strong predictor of better functional outcome after surgery. Functional outcome was concluded from LV dimension changes over the changes of LVEF, LA or LAVI. There was no correlation between day of echocardiography in this study was performed with the changes of LV dimension, exact time course of LV remodelling still need further study.

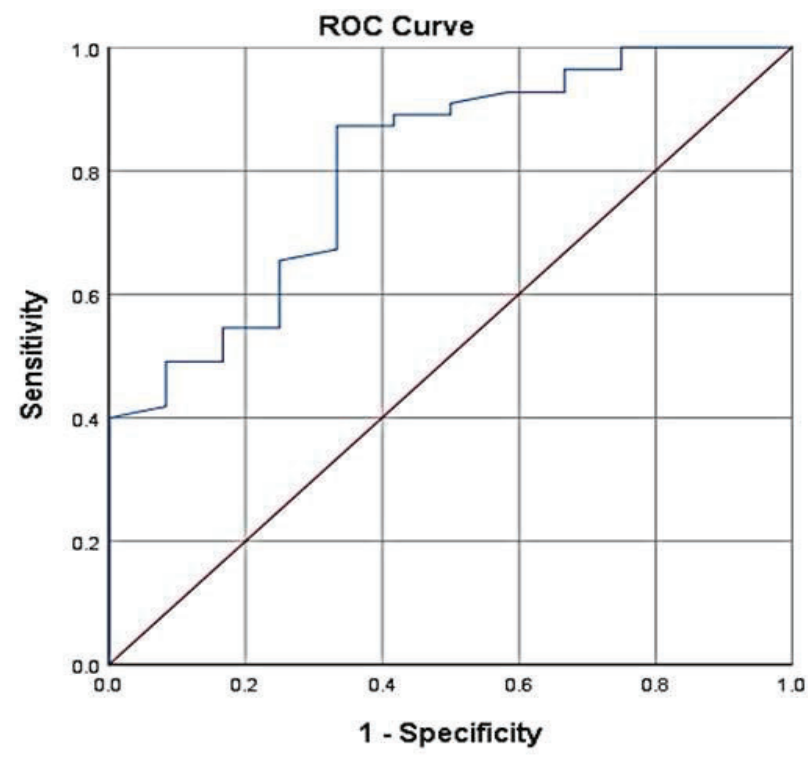

Figure 2. ROC curve for EDV and decreasing LV dimension after surgery.

\section{LVEF and stroke volume}

Ejection fraction from many studies show a fluctuative result that not always accordance to clinical patient's manifestation, thus not always become the only parameter in making decision for timing of surgery. Patient with compensated severe MR, increased preload and LV volume and dereased afterload maintain LVEF within normal or supernormal values for long period. ${ }^{15,16}$ LVEF shows to be increased in long time follow up, reflecting normalization of LV systolic function after surgery. ${ }^{17}$ Relative impairment of LV performance also 
possibly occur, showed by significant decrease LVEF and stroke volume acutely after operation with a partial recovery at long-term follow up. ${ }^{18,19}$ In other study, both forward stroke volume and forward LVEF significantly increased immediately after successful correction of MR. $^{20}$

\section{LA dimension and LAVI}

This study showed no significant correlation between LA dimension and LAVI with decreasing of LV dimension. Previous studies show parameter LA and LAVI, that found to be predictors of outcome. ${ }^{21,22}$ Left atrial reverse remodelling (LARR) as a mechanism of LA and LAVI changes after mitral surgery, occured during early postoperative period. LV global longitudinal strain, age and LA volume at surgery determined the degree of early LARR after MV surgery in patient with chronic severe MR. ${ }^{21}$ LARR occured frequently after mitral valve surgery and is associate with preoperative LVEF higher than 63.5\%. ${ }^{22}$ Preoperative LAVI, bood pressure, postoperative transmitral mean pressure gradient, residual $\mathrm{MR}$, and age $>45$ were related to LAVI reduction. ${ }^{23}$

\section{End-diastolic volume}

Significant correlation between end-diastolic volume and decreasing LV dimension after surgery was found in this study $(\mathrm{p}<0.001)$. There is EDV tresh hold of $133.5 \mathrm{ml}$ (sensitivity $87.3 \%$, specificity $66,7 \%$ ) for best functional outcome after surgery. Previous study showed significant changes overtime in LV end-diastolic $(\mathrm{p}<0.001)$ and end-systolic $(\mathrm{p}=0.009)$ volume index. Immediately after mitral valve repair, both LV enddiastolic and end systolic volume indices decreased significantly in comparison with baseline $(p<0.001)$, but the reduction in $\mathrm{LV}$ end-diastolic volume index was more pronounced. At long-term follow up, LV end-diastolic volume index showed significant increase $(p<0.001)$ but remained signficantly smaller in comparison with baseline values $(\mathrm{p}<0.001){ }^{20}$

\section{Mitral regurgitant volume}

Significant correlation between mitral regurgitant volume and decreasing LV dimension after surgery was found in this study $(\mathrm{p}=0.05)$. No significant correlation was found between ratio of mitral regurgitant volum to end-diastolic volume and decreasing of LV dimension after surgery in this study $(\mathrm{p}>0.05)$. Mitral regurgitant volume is common evaluation during chronic phase of MR, to determine the mitral regurgutation severity. Two randomized clinical trials analyzed the ratio of mitral regurgitant volume to end-diastolic volume was performed in different study population compared with this study. Those were in population of transcatheter edge-to-edge mitral valve repair with secondary mitral regurgitation..$^{24}$

\section{Study Limitations}

End-diastolic volume as a predictor for mitral surgery outcome, needs further study with longer period of echocardiography measurement, before and after surgery. This is a retrospective analysis with limited echocardiographic measurement. Prospective study with more new parameters will give accurate parameter for predicting best outcome of mitral corrective surgery.

\section{Conclusion}

End-diastolic volume and regurgitant volume before mitral corrective surgery showed significant correlation with decreasing LV dimension after surgery, that is make them potential to become echocardiography parameters in predicting better functional outcome after mitral surgery. End-diastolic volume 133,5 $\mathrm{ml}$ or more will give better predictive outcome after surgery. Measuring both parameters will be helpful in determine optimal timing of surgery.

\section{Acknowledgment}

We thank Dr. dr. Iwan Dakota, SpJP(K), MARS, FIHA, FESC, FACC, FSCAI as President Director National Heart Center Harapan Kita, dr. Renan Sukmawan, SpJP(K), PhD, FIHA, FACC as head of Cardiology and Vascular Medicine Department and the echocardiography team of National Heart Center Harapan Kita for support of the manuscript. 


\section{References}

1. Gaasch WH, Levine HJ, Zile MR. Chronic aortic and mitral regurgitation: mechanical consequences of the lesion and the results of surgical correction. In: Levine HJ, Gaasch WH, eds. The Ventricle. Boston, Mass: Martinus Nijhoff; 1985: 237-258.

2. Ross J Jr. Afterload mismatch in aortic and mitral valve disease: implications for surgical therapy. J Am Coll Cardiol. 1985; 5: 811-826

3. William H. Gaasch and MD Theo E. MeyerMD, $\mathrm{PhD}$ From the Departements of Cardiovascular Medicine, Lahey Clinic, Burlington, Mass, and University of Massachusetts Medical School, Worcester, Mass. Left Ventricular Response to Mitral Regurgitation. Implications for Management. Circulation. 2008.

4. Le Tourneau T, Messika-Zeitoun D, Russo A, Detaint D, Topilsky Y, Mahoney DW, Suri R \& Enriquez-Sarano M 2010 Impact of left atrial volume on clinical outcome in organic mitral regurgitation. Journal of the American College of Cardiology 56 570-578. (doi:10.1016/j.jacc.2010.02.059)

5. Grigioni F, Avierinos JF, Ling LH, Scott CG, Bailey KR, Tajik AJ, Frye RL \& Enriquez-Sarano M 2002 Atrial fibrillation complicating the course of degenerative mitral regurgitation: determinants and long-term outcome. Journal of the American College of Cardiology 40 84-92. (doi:10.1016/ S0735-1097(02)01922-8)

6. Enriquez-Sarano $M$, Suri RM, Clavel MA, Mantovani F, Michelena HI, Pislaru S, Mahoney DW \& Schaff HV 2015 Is there an outcome penalty linked to guideline-based indications for valvular surgery? Early and long-term analysis of patients with organic mitral regurgitation. Journal of Thoracic and Cardiovascular Surgery 150 50-58. (doi:10.1016/j.jtcvs.2015.04.009)

7. Flemming MA, Oral H, Rothman ED, Briesmiester K, Petrusha JA, Starling MR. Echocardiographic markers for mitral valve surgery to preserve left ventricular performance in mitral regurgitation. Am Heart J 2000;140:476-82.

8. Christophe Tribouilloy, Dan Rusinaru, Catherine Szymanski, Sonia Mezghani, Alexander Fournier, Franck Levy, Marcel Peltier, Ammar Ben Ammar, Doron Carmi, Jean-Paul Remadi, Thierry Caus,
Gilles Touati. Predicting left ventricular dysfunction after valve repair for mitral regurgitation due to leaflet prolapse: additive value of left ventricular endsystolic dimension to ejection fraction. European Journal of Echocardiography. 2011;12:702-710.

9. Boyang Liu, Nicola C Edwards, Simon Ray, Richard P. Steeds. Timing surgery in mitral regurgitation: defining risk and optimising intervention using stress echocardiography. Downloaded from Bioscientifica. com at 03/10/2020 12:13:08PM via free access.

10. Crawford MH, Souchek J, Oprian CA, Miller DC, Rahimtoola S, Giacomini JC, et al. Determinants of survival and left ventricular performance after mitral valve replacement. Department of Veterans Affairs Cooperative Study on Valvular Heart Disease. Circulation 1990;81:1173-81.

11. Hyue Mee Kim, Goo-Yeong Cho, In-Chang Hwang, Hong-Mi Choi, Jun-Bean Park, Yeonyee E. Yoon, Hyung-Kwan Kim. Myocardial strain in Prediction of Outcomes After Surgery for Severe Mitral Regurgitation. J Am Coll Cardiol Img. 2018;11: 1235- 44.

12. Jong-Min Song, Se Hun Kang, Eun-Jeong Lee, Min-Jung Shin, Jae Won Lee, Cheol Hyun Chung, Dae-Hee Kim, Duk-Hyun Kang, Jae-Kwan Song. Echocardiographic Predictors of Left Ventricular Function and Clinical Outcomes After Successful Mitral Valve Repair: Conventional Two-Dimensonal Versus Speckle-Tracking Parameters. Ann Thorac Surg 2011;91: 1816-23.

13. Lang RM, Badano LP, Mor-Avi V, et al. Recommendations for cardiac chamber quantification by echocardiography in adults: an update from the American Society of Echocardiography and the European Association of Cardiovascular Imaging. J Am Soc Echocardiogr 2015;28:1-39.e14.

14. Zoghbi WA, Adams D, Bonow RO, Enriquez-Sarano M, Foster E, Grayburn PA, et al. Recommendations for non-invasive evaluation of native valvular regurgitation: A report from the American Society of Echocardiography developed in collaboration with the Society for Cardiovascular Magnetic Resonance. J Am Soc Echocardiogr doi:10.1016/j. echo.2017.01.007.

15. Bonow RO, Carabello BA, Chatterje $\mathrm{K}$, e $\mathrm{t}$ al. ACC/AHA 2006 guidelines for managemnet of 
patient with valvular heart disease: a report of the American College of Cardiology/ American Heart Association Task Force on Practice Guidelines. J Am Coll Cardiol 2006.;48:48:e1-148.

16. Vahanian A, Baumgartner H, Bax J, et al. Guidelines on the management of valvular heart disease. The Task Force on teh Management of Valvular Heart Disease of The European Society of Cardiology. Eur Heart J 2007;28:230-68.

17. Tomasz GW, James DT, Victoria D, et al. Changes in Left Ventricular Function After Mitral Valve Repair for Severe Organic Mitral Regurgitation. Ann Thoracic Surg 2012;93:754-60.

18. Clancy KF, Hakki AH, Iskandrian AS, et al. Forward ejection fraction: a new index of left ventricular function in mitral regurgitation. Am Heart J 1985;110:658-64.

19. Enriquez-Sarano M, Bailey KR, Seward JB, Tajik AJ, Krohn MJ, Mays JM. Quantitative Doppler assesment of valvular regurgitation. Circulation 1993;87:841-8.

20. Braunwald E. Mitral regurgitation: physiologic, clinical and surgical considerations. N Engl J Med 1969;281:425-33.

21. Peter C, Chi Young S, Geu-Ru H, et al. Time course of left atrial reverse remodelling after mitral valve surgery and the impact of left ventricular global longitudinal strain in patients with chronic severe mitral regurgitation. Interactive CardioVascular and Thoracic Surgery 2016;23:876-882.

22. Lucia RM, Zilda MM, David CS, et al. Preoperative left ventricular ejection fraction and left atrium reverse remodelling after mitral regurgitation surgery. Cardiovasc Ultrasound 2014;12:45.

23. F Antonini-Canterin et al. Left Atrial Remodelling Early After Mitral Valve Repair for Degenerative Mitral Regurgitation. Heart 2008 Jul;94(7):935.

24. Philippe P, Victoria D, Jeroen JB. MITRA-FR vs COAPT: lessons from two trials with diametrically opposed results. European Heart JournalCardiovascular Imaging 2019;20:6:620-624. 